\title{
Simon Gundelfinger, Peter Verkinderen. "The Governors of al-Shām and Fārs in the Early Islamic Empire - A Comparative Regional Perspective"
}

\section{Dariouche Kechavarzi}

\section{(2) OpenEdition \\ 1 Journals}

\section{Édition électronique}

URL : https://journals.openedition.org/abstractairanica/52859

DOI : 10.4000/abstractairanica.52859

ISSN : 1961-960X

Éditeur :

CNRS (UMR 7528 Mondes iraniens et indiens), Éditions de l'IFRI

\section{Référence électronique}

Dariouche Kechavarzi, «Simon Gundelfinger, Peter Verkinderen. "The Governors of al-Shām and Fārs in the Early Islamic Empire - A Comparative Regional Perspective" ", Abstracta Iranica [En ligne],

Volume 42-43 | 2021, document 5, mis en ligne le 30 juillet 2021, consulté le 14 décembre 2022. URL : http://journals.openedition.org/abstractairanica/52859; DOI : https://doi.org/10.4000/

abstractairanica.52859

Ce document a été généré automatiquement le 14 décembre 2022.

Tous droits réservés 


\title{
Simon Gundelfinger, Peter Verkinderen. "The Governors of al- Shām and Fārs in the Early Islamic Empire - A Comparative Regional Perspective"
}

\author{
Dariouche Kechavarzi
}

\section{RÉFÉRENCE}

Simon Gundelfinger, Peter Verkinderen. "The Governors of al-Shām and Fārs in the Early Islamic Empire - A Comparative Regional Perspective" in H.-L. Hagemann, S. Heidemann (eds.). Transregional and Regional Elites - Connecting the Early Islamic Empire. The Early Islamic Empire at Work. vol. 1, Berlin: De Gruyter, 2020, p. 255-329.

1 Cette étude traite de la gestion des provinces de l'Empire musulman par le pouvoir califal, des débuts de l'ère omeyyade ( $\mathrm{I}^{\mathrm{er}} / \mathrm{VII}{ }^{\mathrm{e}}$ siècle) jusqu'au règne du calife abbaside al-Mu'tamid (m. 279/892). Les auteurs proposent une analyse comparative des logiques qui président à la nomination des gouverneurs dans les provinces du Fārs et du Shām. Dans une approche prosopographique, les noms de tous les gouverneurs de ces deux régions sont compilés à partir d'un corpus numérisé de plusieurs milliers de traités historiographiques médiévaux, ainsi que d'ouvrages prosopographiques et de sources numismatiques (voir tableau p. 295-329). À travers la comparaison du profil des gouverneurs nommés dans ces provinces, les auteurs analysent la relation des califats successifs à chacun de ces territoires, et mettent ainsi en lumière l'évolution des modes de gouvernement spécifiques qui s'y appliquent au gré des tensions politiques locales ou internes au califat. Outre sa méthode originale, cette étude permet de mieux saisir comment le pouvoir califal fonctionne localement et se diffuse dans les périphéries de l'empire, remédiant ainsi à la concentration de la tradition historiographique 
musulmane sur les capitales califales. Notons enfin que la notion d'« ethnicité » («arabe»/«non-arabe» ou «iranien») des gouverneurs, qui sert aux auteurs de critère d'analyse principal, mériterait d'être mieux définie dans son contexte médiéval et islamique.

\section{AUTEURS}

DARIOUCHE KECHAVARZI

Doctorant, LEM (EPHE)/LabEx HASTEC 